\section{Géneros}

Multidisciplinary Journal of Gender: Studies

\section{Hipatia Press \\ www.hipatiapress.com}

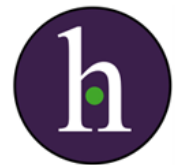

Instructions for authors, subscriptions and further details:

http://generos.hipatiapress.com

\title{
Esclavitud, Género y Racialización en Alicante: La Colonización de los Cuerpos Femeninos (ss. XVII-XVIII).
}

Lydia Delicado-Moratalla ${ }^{1}$

1) Universidad de Alicante. España.

Date of publication: June $25^{\text {th }}, 2017$

Edition period: June - October 2017

To cite this article: Delicado-Moratalla, L. (2017). Esclavitud, Género y Racialización en Alicante: La Colonización de los Cuerpos Femeninos (ss. XVII-XVIII). Multidisciplinary Journal of Gender Studies, 6(2), 1334-1360. doi: 10.4471/generos.2017.2464

To link this article: http://dx.doi.org/10.4471/generos.2017.2464

\section{PLEASE SCROLL DOWN FOR ARTICLE}

The terms and conditions of use are related to the Open Journal System and to Creative Commons Attribution License (CC-BY). 
GÉNEROS-Multidisciplinary Journal of Gender Studies Vol. 6 No. 2 June 2017 pp. 1334-1360

\section{Slavery, Gender and Racialization in Alicante: The Colonization of Female Bodies $\left(17^{\text {th }}-18^{\text {th }}\right.$ Centuries)}

Lydia Delicado-Moratalla

Universidad de Alicante

\section{Abs tract}

This article examines the slaver commercialization on black African women in the Seventeenth and Eighteenth centuries in the city of Alicante, within the context of a comparative study between the past and the present about Nigerian women's sex trafficking. From a theoretical and methodological framework based on feminist and antiracist geographies, using a decolonial lens, I present a gender and race analysis of the Alicantinian slavery process, in addition to its cultural and social impacts. Thus, I tackle the racialization, colonization and commodification of bodies as a violent mechanism of women's dehumanization. At the same time, I review the androcentric bias of the historiographic discourse about the Peninsular slavery in the Hispanic Modern Age.

Keywords: slavery, feminist geography, racialization, decolonial feminism, black women 
GÉNEROS-Multidisciplinary Journal of Gender Studies Vol. 6 No. 2 June 2017 pp. 1334-1360

\section{Esclavitud, Género y Racialización en Alicante: La Colonización de los Cuerpos Femeninos (ss. XVII-XVIII)}

Lydia Delicado-Moratalla

Universidad de Alicante

\section{Resumen}

En este artículo examino la comercialización esclavista de mujeres negro africanas en los siglos XVII y XVIII en la ciudad de Alicante, en el contexto de un estudio comparativo entre el pasado y el presente sobre trata con fines de explotación sexual de mujeres nigerianas. Desde el marco teórico y metodológico de las geografías feministas y antirracistas, con un prisma decolonial, presento un análisis de género y de raza sobre el proceso de esclavización alicantino, así como sus repercusiones sociales y culturales. Abordo la racialización, la colonización y la mercantilización de los cuerpos, como una causa violenta de deshumanización de las mujeres, al mismo tiempo que reviso el sesgo androcentrista del discurso historiográfico sobre la esclavitud peninsular de la era moderna hispánica.

Palabras clave: esclavitud, geografía feminista, racialización, feminismo decolonial, mujeres negras

2017 Hipatia Press

ISSN: 2014-3613

doi: 10.4471/generos.2017. 2464

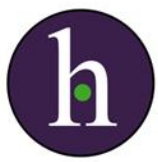




\section{Delicado-Moratalla - Cuerpos racializados}

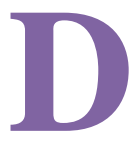

esde finales del siglo XV y en los inicios del siglo XVI, el comercio esclavista negrero funcionaba dentro del territorio peninsular hispánico. El mercado que tuvo mayor trascendencia, donde las personas del occidente africano eran mercantilizadas, fue el de Sevilla (Martín Casares \& García Barranco, 2010). Pero no fue el único. También surgió, entre otras, en las ciudades mediterráneas. Mi interés de indagar en estas esferas del pasado nace a raíz de investigar, desde la geografía feminista contemporánea, los posibles antecedentes históricos de la trata con fines de explotación sexual de mujeres nigerianas en Alicante, que viene dándose con creces en el siglo XXI en España y en el contexto europeo (Eurostat, 2015; Women's Link Worldwide, 2014). Entiendo que la trata de mujeres negro africanas para la esclavitud durante la era moderna hispánica tuvo características comunes con los acontecimientos actuales, por lo que la pregunta inicial para esta investigación fue si hubo mujeres del África Negra objeto de comercio esclavista anteriormente en la villa alicantina.

\section{Interseccionalidad y feminismo decolonial}

Analizo en este artículo las compraventas que se realizaron en Alicante durante los siglos XVII y XVIII, desde una perspectiva interseccional y feminista decolonial, en la que incido en los aspectos de raza y de género que fueron característicos en la esclavización de las mujeres del África Negra. La interseccionalidad (Crenshaw, 1991) es un concepto a través del cual comprendemos que las relaciones sociales nunca están marcadas por un solo factor. Algunas geógrafas feministas antirracistas consideran, de hecho, que la perspectiva interseccional es imprescindible para comprender y escribir sobre la subordinación femenina (Mollett \& Faria, 2013). La interseccionalidad es una herramienta de trabajo: "examina cómo las relaciones de poder están interconectadas y mutuamente constituidas" (Hill Collins \& Bilge, 2016, p. 7). Según Gill Valentine, el concepto "se utiliza para teorizar la relación entre diferentes categorías sociales: género, raza, sexualidad y otras" (Valentine, 2007, p. 10).

El feminismo decolonial, asumido dentro del pensamiento feminista antirracista en geografía (Faria \& Mollett, 2016; McKittrick, 2006; McKittrick \& Woods, 2007), es imprescindible para comprender la 
diáspora africana, aboga por una nueva epistemología (Mendoza, 2014), que no esté sesgada ni protagonizada por la herencia colonial.

La colonialidad de género es un concepto acuñado por María Lugones (2008) con el que alude a la expansión del patriarcado que trajo consigo la colonización en pueblos en los que las relaciones sociales no estaban previamente impregnadas por la marginalidad de género. Breny Mendoza considera que las mujeres del mundo colonizado "no sólo fueron racializadas, sino que al mismo tiempo fueron reinventadas como 'mujeres' de acuerdo a códigos y principios discriminatorios de género occidentales" (Mendoza, 2014, p. 93).

\section{La racialización}

Por racialización entendemos el proceso de atribuir una categoría de raza a una persona o colectivo de personas, formando con ello una jerarquía a través de la construcción de la diferencia. Dicha diferenciación, finalmente, se inscribe sobre los cuerpos, es decir, se corporaliza (Brahinsky, Sasser, \& Minkoff-Zern, 2014), de manera que, sobre mi objeto de estudio (las mujeres negro africanas) "los cuerpos de las mujeres negras son construcciones sociales, políticas y raciales" (Moharam, 1999, p. 45).

Ha sido frecuente en geografía asumir la experiencia de las personas blancas occidentales, al igual que la masculinidad, como una realidad extensible a las geografías de todos los seres humanos y todos los territorios. En ocasiones se habla de racismo, raza o racialización cuando se estudian sujetos o lugares no identificados como blancos, es decir, cuando participan de la investigación y del discurso los sujetos y espacios que representan la diferencia, lo otro. Los seres blancos se han considerado en la tradición geográfica como exentos de racialización o como "los seres por defecto" (Gillen, 2016, p. 585) y esa idea estaba imbuida de la consideración de la blancura (whiteness en su denominación original), como aquello neutral y normativo. El concepto de whiteness corresponde a "una identidad racializada estrechamente ligada al poder y al privilegio" (Gregory, Johnston, Pratt, Watts, \& Whatmore, 2009). La blancura es la identidad de los cuerpos blancos occidentales, y actúa constituyéndose como la corporalización del privilegio.

Laura Pulido (2002) destacó la importancia de observar los hechos desde el enfoque de raza. Algo urgente, pues "ningún aspecto de la 
disciplina, ni ninguna teoría espacial ha escapado de la racialización" (Peake \& Kobayashi, 2002, p. 50). Así, las citadas autoras, que también han escrito una prolífica literatura feminista (Kobayashi, 2006; Kobayashi \& Peake, 1994; Peake \& Rieker, 2013; Staeheli, Kofman, \& Peake, 2004) animaron a pensar desde el enfoque de raza y a introducirlo tanto en la investigación como en la enseñanza de la geografía, además de en la estructura de las instituciones académicas.

En este artículo, me interesa analizar el racismo y la racialización que operó sobre las mujeres negras esclavizadas en el pasado alicantino, pues su estudio arroja luz para comprender su pervivencia en la trata de mujeres nigerianas del siglo XXI. Para ello transcribo y examino los contenidos de cuatro documentos originales de archivo en los que se detallan aspectos relevantes que podemos identificar con un proceso de racialización. Esta metodología ya ha sido previamente empleada en otras investigaciones, particularmente, desde la perspectiva interseccional raza-género. La referencia más destacada en España es el trabajo de Aurelia Martín Casares (2000b, 2014b), quien evidenció el interés existente en los documentos históricos en inscribir la diferencia de los cuerpos a partir de la descripción detallada de matices respecto al color de la piel de las esclavizadas en Granada.

\section{Esclavizadas y racializadas: muje res del África Negra en Alicante (ss. XVII y XVIII)}

Conocemos la presencia de mujeres negro africanas esclavizadas en ciudades como Granada (Martín Casares, 2000b), Sevilla (Martín Casares \& García Barranco, 2010), Valencia (Cortés Alonso, 1972) y el territorio extremeño (Periáñez Gómez, 2009b). Me preguntaba si también hubo mercadeo esclavista en la villa alicantina de la modernidad y cómo se producía la compraventa, quiénes eran aquellas personas que adquirían esclavizadas y en qué términos se ocasionaba el comercio.

Consideradas como parte de la carga en las embarcaciones que arribaban a puerto, ya entre 1482 y 1516 , setenta y nueve mujeres negro africanas fueron registradas en la vecina Valencia (Cortés Alonso, 1972). Si bien no hemos localizado un número tan elevado para el caso alicantino, nos suscita especial interés centrarnos en los términos en los que se produjo la venta de 
mujeres negro africanas en Alicante, pues las palabras son muy llamativas en las cartas de venta, escritas por notarios y archivadas en la sección de protocolos notariales del Archivo Histórico Provincial de Alicante (AHPA), así como en documentos hallados en los legajos del Archivo Histórico Municipal de Alicante (AHMA) y el Archivo del Reino de Valencia (ARV).

Dichas cartas, evidencian cómo la diferencia racial inscrita sobre los cuerpos femeninos, fue comercializada. Estos documentos de la era moderna hispánica muestran una categorización en base a distintos colores de piel en las esclavizadas. Las descripciones sobre las múltiples tonalidades demuestran cuán interesante es este proceso de diferenciación como mecanismo de producción de racialización, es decir, como motor de construcción social de la diferencia y la subordinación. Aurelia Martín Casares (2000a) ya se hizo eco de ello al investigar el mundo de la esclavitud en la Granada del siglo XVI. La creación de esta situación de subordinación de las esclavizadas de origen africano estaría en el marco de la colonización de género que expresó Lugones (2008).

En las cartas de venta leemos las categorías de color descritas como negra tesada, negra, cetrina y africana blanca. El protocolo notarial se escribía con sumo detalle en lo referente a las características del 'producto' humano, esclavizadas como bienes de consumo. Especial atención era depositada en cada marca, señal, tamaño, edad y características corporales de las mujeres. Consecuentemente, consideradas aquellas mujeres seres Otros, desplazados forzosamente de sus territorios de origen, la racialización se manifestó como un proceso de creación de desigualdades, lo que evidencia que

el concepto de la diferencia posibilita la construcción social de categorías de personas subordinadas a una norma dominante, y permite la continuación de las prácticas culturales que reinscriben la diferencia como valores de diferenciación localizados en la vida humana (Kobayas hi, 1995, p. 3).

Ambroza era el primer nombre conocido de una joven esclavizada que llegó al puerto alicantino en el año 1666 procedente de Orán, en el norte de África, traída por Nicolás Alemunda y que fue renombrada como Jusepa María. A su llegada, éste pagó el preceptivo impuesto al reino, como era 


\section{Delicado-Moratalla - Cuerpos racializados}

habitual, llamado "quinto", que fue recogido por el Bayle de la ciudad. La Corona exigía el "quinto" y la "licencia", es más, algunas licencias para ir a Guinea, de hecho, eran compradas directamente al Rey; Carlos I monopolizó el comercio mediante la creación del "asiento" y otros pagaban mediante esclavos, de lo que se desprende que las autoridades estuvieron vinculadas con el desarrollo de la explotación esclavista (Cortés López, 1986). Precisamente, a la vez que prosperó este gran negocio, también lo hizo el mercado ilegal, pues de este modo, se evadía el pago de dichos impuestos.

En ese momento, Jusepa María, siendo una adolescente de 14 años de edad, fue mercantilizada y vendida como esclava a Antonio Basset. Once años después de su llegada a la villa alicantina, fue nuevamente vendida a un comprador murciano, llamado Turivio Valdrés, en 1677:

yo Antonio Basset hombre de negocios, vecino y morador de esta ciudad de Alicante (...) que vendo y por título de venta, libro y entrego a Turivio Valdrés, escribano público vecino de la ciudad de Murcia (...) una esclava cristiana mía propia, sujeta a servidumbre, nombrada Jusepa Maria, de edad de veinticinco años (...), de buena estatura, color negro tesado, buen aspecto y sin ninguna señal, la cual trajo de Orán (...) y llamada Ambroza (...) fue quintada por el Bayle General de esta Ciudad de Alicante (...) y me desapodero, desisto y aparto de la posesión, propiedad, dominio y señorío y de todo el derecho, acción y título que tengo y me compete en la dicha esclava. Y en todo ello apodero, cedo, renuncio y traspaso en y al dicho Turivio Valdrés para que sea suya propia, para poder darla, vender, enajenar y hacer de ella lo que quisiere y bien vis to le fuere, como de cosa suya propia, comprada con su dinero y adquirida por justo y derecho título (Basset, 1677).

La carta de venta arroja con claridad los términos en los que una mujer negra era comercializada con fines de esclavitud. Descrita como negra tesada, se especifica que tenía buen tamaño y buena apariencia, sin tacha alguna, aspectos que comprendo que fueron prioritarios para el deseo de la compra. La esclavizada, en este texto es descrita como una propiedad, como cualquier otro bien, bajo el dominio de Turivio Valdrés, a quien le es otorgado el poder de hacer con ella todo lo que quisiera, pues siendo suya propia y adquirida con su dinero, estaría bien visto. La normalidad con la 
que una mujer es cosificada, clasificada y mercantilizada es un aspecto relevante en la escritura, lo que, a su vez, supone un proceso de deshumanización (Mollett, 2016) de las esclavizadas.

Los detalles en las cartas de venta son diversos. En la escritura de entrega de Caterina, identificada como una esclava negra, se explica que posee una cicatriz en la mejilla izquierda, así como aspectos de su conducta, la cual se promociona como dócil y sin ningún antecedente criminal. Aspectos referidos a la salud de la esclavizada también resultan relevantes, por lo que desprendemos que el protocolo notarial ofrecía las buenas características del producto en el momento del trato. Al igual que el caso de Jusepa María, observo la insistencia de reflejar a la persona como una posesión:

yo Don Antonio Arnaut, de nación genovés, capitán del navío (...) otorgo que vendo y doy en venta real a Don Domingo Grasi, negociante vecino de esta dicha ciudad, una esclava negra mía propia, cautiva (...), llamada Caterina de buena ... cicatriz en la mejilla izquierda, de edad de veinticuatro años, ni hipotecada ni sujeta a ninguna obligación de deuda mía y no ha cometido delito ninguno criminal por donde merezca pena corporal, sana de toda enfermedad pública o secreta de mal de corazón ... no fugitiva ni ladrona ni conoce ningún defecto ni tacha que le impida servir bien (Grassi, 1723).

De igual modo, otras mujeres de procedencia (negro) africana habitaron la ciudad bajo el yugo de la esclavitud: 
Tabla 1

Esclavizadas negro africanas en Alicante. Detalle de la diferenciación racial que ofrecen las cartas de venta de los protocolos notariales.

\begin{tabular}{|c|c|c|c|c|c|c|}
\hline NOMBRE & PROCEDENCIA & EDAD & COLOR & AÑO & DOCUMENTO & ARCHIVO \\
\hline Francesca & - & $28(i ?)$ & Negro & 1609 & $\begin{array}{c}\text { Poder } \\
\text { otorgado para } \\
\text { la venta }\end{array}$ & ARV \\
\hline $\begin{array}{c}\text { Jusepa } \\
\text { María }\end{array}$ & Orán & 25 & $\begin{array}{c}\text { Negro } \\
\text { tesado }\end{array}$ & 1677 & Carta de venta & AMA \\
\hline Otavia & Africana & 16 & Blanco & 1714 & Carta de venta & AHPA \\
\hline Caterina & - & 24 & Negro & 1723 & Carta de venta & AHPA \\
\hline María & Africana & 30 & Blanco & 1727 & $\begin{array}{c}\text { Carta de } \\
\text { libertad }\end{array}$ & AHPA \\
\hline María Pérez & - & 34 & Cetrino & 1733 & Carta de venta & AHPA \\
\hline
\end{tabular}

Fuente: elaboración propia

Observo en los datos ofrecidos, que las mujeres esclavizadas eran jóvenes en el momento de la venta, incluso también en el de la liberación. Otavia y María aparecen categorizadas como blancas, pero han sido objeto de esta investigación al haber sido reconocidas como africanas. En sus documentos de compra venta, las esclavas eran identificadas con nombres castellanos, lo que da muestra de cómo se les cambiaba la identidad africana por una nueva. No es habitual encontrarlas con apellido, pero aquí, como vemos, María Pérez sí quedó registrada como tal:

sepa por esta escritura que yo, Don Francisco Ruiz de Amoriaga (...) vendo y doy en venta real a Don Juan de Goyeneche (...) vecino de esta ciudad de Alicante, una mía esclava habida de buena guerra, llamada María Pérez, color cetrino, herrada con hierro en la frente, de unos treinta y cuatro años de edad, no hipotecada ni sujeta a deuda ni obligación mía, ni cometió delito que merezca pena corporal, sana de enfermedad, mal de corazón...(De Goyeneche, 1733). 
A través de las menciones referidas a que sus conductas no habían merecido castigo corporal, desprendemos que fue habitual infligir en ellas tales violencias en caso de reprobación. Asimismo, comprobamos que la esclavitud se forjaba a hierro candente. María Pérez estaba herrada a fuego en la frente, lo que nos indica la brutalidad con la que eran tratadas. Escalofriante resulta leer la descripción de todas las marcas herradas que las esclavizadas tenían en su rostro, como resultado del proceso de deshumanización inherente a la esclavización:

una esclava suya propia, africana de nación, llamada Otavia, de buen cuerpo, blanca, de edad según su aspecto, de unos diez y seis años poco más o menos, herrada en la frente, barba, nariz y carrillo, sujeta a forzosa servidumbre (Gómez de Villanueva, 1714).

dijo que por cuanto tiene una esclava africana de nación, llamada María, de buen cuerpo, blanca y según su aspecto, de unos treinta años poco más o menos, herrada en la frente, barba, nariz y carrillo, que la pertenece (Protocolo notarial, 1727).

Los términos en los que se establecían las ventas y el herraje en el rostro, se realizaban en un marco que pretendía aproximar a las esclavas negras al mundo de la bestialidad. Ese pretendido salvajismo de la población negro africana era el estereotipo adecuado para justificar toda pauta de abusos y aberraciones y fue el contexto en el que también se desarrolló la idea de las mujeres negro africanas hipersexualizadas. Así, como apunta Joane Nagel (2003, p. 96), “dentro de esta tradición pornotrópica, las mujeres [africanas] figuraban como el arquetipo de exceso y aberración sexual. (...) se las mostraba entregadas a una veneración lasciva tan promiscua que estaba al borde de la bestialidad". Es por ello que, en semejante contexto, en la era moderna, los términos de venta de Jusepa María, que otorgaban derecho a Turivio Valdrés a hacer con ella lo que él quisiera, los entendemos, no sólo como subordinación, sino también en cláusulas sexualizadas.

En otros territorios, como en América del norte, sabemos, adicionalmente, que fue muy lucrativo mercantilizar a las esclavizadas bajo el arquetipo hipersexual. Los vendedores aprovecharon "ese especial atractivo morboso" y las "imágenes morbosas sobre la sexualidad africana 


\section{Delicado-Moratalla - Cuerpos racializados}

sirvieron muy bien a los intereses de los que vendían esclavas negro africanas" (Nagel, 2003, p. 96). De manera que pensamos que fue posible que los negociantes dedicados a la compra y venta de mujeres esclavizadas se aprovechasen de tal imaginario con el objetivo de obtener mejor ganancia de la mercancía humana femenina.

Las evidencias encontradas (Cortés López, 1986), en las que las personas negras eran símbolo de bajeza y abyección en la sociedad hispánica, indican que fue común reproducir ideas estereotipadas sobre los seres en esclavitud, atribuyéndoles características como la docilidad, la sexualidad desaforada, la falta de inteligencia o la brutalidad y, además, representadas desde la antítesis, como indica Morgado García (2010, p. 56), "lo negro frente a lo blanco" o "lo bárbaro, salvaje o aborigen frente a lo occidental". Fue habitual, de hecho, escuchar, a pie de calle, las referencias a los negros y negras como “'negros bozales', individuos 'sin razón', 'gente ridícula', 'causantes de escándalo' y poseedores de una 'natural inclinación a los delitos públicos"” (Méndez Rodríguez, 2010, p. 114). Según María Lugones (2012), una de las consecuencias de la colonización sobre las personas fue la creación de un mundo dicotómico, como hemos dicho, lo negro fue lo antagónico de lo blanco, en el que por humano - dueño de la razón y del conocimiento - se consideró al hombre blanco occidental y poderoso, mientras que aquello no-humano - sin razón ni conocimiento eran los atributos para el resto de la población. Las mujeres blancas, si bien no eran consideradas dueñas de la razón ni del conocimiento por marginación de género, fueron pensadas como humanas en tanto que eran quienes tenían la gracia de reproducir la especie. Por lo tanto, el trato desde lo no-humano, la bestialidad y lo salvaje, fue el comportamiento social habitual hacia la población esclava. Desde esta explicación, podemos pues comprender aquellos comentarios peyorativos y racistas que las personas en las calles sevillanas hacían de la población negra y afrodescendiente.

En lo que respecta a los compradores de esclavas en el Alicante del XVII y XVIII, son hombres de un estamento social medio-alto. Turivio Valdres, era escribano en la vecina ciudad de Murcia. Juan Domingo Grasi [también encontrado como "Grassi"], comprador de Caterina, era un negociante de Alicante, quien recibió la esclava propiedad de Antonio Arnaut, genovés y capitán de navío. Francisco Sánchez, secretario y corsario real adquirió a Otavia, vendida por Francisco Gómez de 
Villanueva, vecino de Alicante. Mariana Pro, viuda de Francisco Sánchez de Pedraza, que fue secretario real y comisario de guerra, entrega carta de libertad a la cautiva María (Protocolo notarial, 1727), dado que Francisco Martínez quiere contraer matrimonio con María y compra a la misma para tal fin. A nombre de Juan de Goyeneche he hallado otra compra de esclavo negro, llamado Antonio Francisco, de dieciocho años de edad (Real Hacienda, 1714). Juan de Goyeneche era administrador de la Real Venta de Tabaco y a su nombre existen más cartas de compra de esclavos en el AHPA, no habilitados para consulta por encontrarse en mal estado de conservación.

Las denominaciones en los documentos oficiales de los procesos inquisitoriales también aluden a una diferenciación por razas cuando se trata de una persona negro africana o afrodescendiente. Con el término mulata hallamos en la sección de la Inquisición del AHN los procesos de Luisa Núñez (Inquisición, 1625), Valentina de Polonia (Inquisición, 1624a) y Juana de Roda (Inquisición, 1624b). Los Tribunales de la Inquisición procesaron a las esclavizadas por acusaciones de hechicería y superstición.

En el año 1624, Juana de Roda, identificada en el documento como esclava mulata de Murcia de 42 años de edad, fue procesada por delito de hechicería, testificada por dos mujeres que habían solicitado sus servicios. De tal manera, que la esclava, le enseñó varios conjuros, descritos en el citado proceso inquisitorial. La rea, que fue reclusa el 6 de julio de 1622 en las cárceles secretas, fue finalmente sentenciada a cuatro años de destierro, considerándose también que había cometido blasfemia heretical al hacer sus acciones en público. Sabemos que para la Inquisición, lo que se consideraba pecado era resuelto y abordado por el confesor, pero los delitos los conformaban aquellas acciones que se cometían en el ámbito público y de las que no se mostraba arrepentimiento. Expresar públicamente algo que iba en contra de la ley católica fue considerado un delito, de lo que se desprende que los tribunales inquisitoriales realizaron una persecución política, tratando de mitigar la oposición o insurrecciones de la población hacia el régimen.

\section{La colonización de los cuerpos}

Desde los inicios de la creación del patriarcado (Lerner, 1990), las mujeres han sido mercadeadas, independientemente de su posición social. Los 
intercambios, habitualmente bajo el control de los varones, se han ido produciendo en acuerdos matrimoniales, en comercio entre tribus y en compraventas esclavistas mayoritariamente. Estas prácticas incluyeron un grado de explotación sexual y reproductiva en las mujeres que, sin embargo, en los hombres esclavizados no tenemos noticia de que se haya producido. Lerner (1990), explicó cómo aquellos procesos de intercambio depararon en la cosificación de la sexualidad y la reproducción de las mujeres. La utilización explotadora de los cuerpos femeninos en el contexto de esclavitud que abordamos en este artículo, supone una usurpación de derechos mediante la colonización de sus cuerpos.

El proceso colonizador que llevaron a cabo los reinos europeos en territorios de ultramar fue sin duda un hecho que marcó definitivamente el devenir de las poblaciones de los continentes. Más allá de la trata negrera y esclavista, de la diáspora africana, del desarraigo y las acciones de brutalidad, de la imposición cultural, política y religiosa que ello supuso, la esclavitud en las mujeres negro africanas fue también una forma de colonizar y explotar sus cuerpos.

Mercantilizar a las esclavas no fue únicamente un acto de subyugar mano de obra productiva en beneficio de un estamento poderoso en la sociedad moderna, sino que además, fue un proceso de apropiación de sus cuerpos, así como de sus derechos sexuales y reproductivos.

Por otra parte, las relaciones extra matrimoniales con mujeres esclavizadas no eran consideradas ni delito ni pecado, el soldado Alonso de Peñalosa, afirmó:

tratando de que un clérigo le comprase una esclava que tenía, dijo que se la comprase que era hermosa y le serviría también de amiga, y diciéndole que era pecado dijo: mira, que pese a Dios llevadla a vuestra casa y estaréis harto de joder y quito de pecado (José Luís Cortés López, 1999, p. 228).

La esclavización de las negro africanas fue un intento "de poner el cuerpo femenino, el útero, al servicio del incremento de la población y la acumulación de fuerza de trabajo" (Federici, 2010, p. 247). Todos estos tratos deshumanizantes (Lugones, 2012) dieron a luz la creación de un estigma en torno a los cuerpos de las mujeres, y también por supuesto de las negras, así como la naturalización del pecado, del abuso y de las prácticas 
perversas. Por lo tanto, como consecuencia, la colonización de sus cuerpos tuvo efectos sobre su posición social, estigmatizándola, marginalizándola, empobreciéndola.

La historia de cómo los cuerpos de las mujeres han sido explotados para diversos fines, nos muestra en multitud de casos que el cuerpo se trata de un territorio, el territorio-cuerpo, también colonizado. Desde el pensamiento feminista latinoamericano decolonial, nace el discurso sobre la huella colonizadora en sus cuerpos, identificando éstos como territorio político:

asumo a mi cuerpo como territorio político debido a que lo comprendo como histórico y no biológico. Y en consecuencia asumo que ha sido nombrado y construido a partir de ideologías, discursos e ideas que han justificado su opresión, su explotación, su sometimiento, su enajenación y su devaluación (Gómez Grijalba, 2012, p. 6).

La temática del cuerpo en la geografía feminista, ha obtenido una especial relevancia, constituyéndose como un gran objeto de estudio, considerándose un territorio y un espacio social, siendo por tanto, eminentemente geográfico. Como señala Josepa Bru (2006, p. 466), el sujeto "humano se ha reformulado en términos de 'embodiment' (corporalización)", siendo fundamental la deconstrucción del sujeto tradicional, puesto que estaba marcado por una característica etnoandrocéntrica que no permitía su consideración diversa. En contraposición, los cuerpos estudiados ahora desde ópticas feministas dan la posibilidad de hablar de sujetos sociogeográficos más reales y plurales. De forma tradicional, se ha hecho una división entre el cuerpo y la mente, destacando en esta última, la razón, aspecto que ha sido históricamente vinculado al mundo masculino (Ortiz Guitart, 2012). Los cuerpos, en el ámbito de lo irracional y lo emocional, han sido igualados al mundo femenino. Las geografías corpóreas rompen esta idea e indagan en las experiencias de los cuerpos como espacios sociales: "el cuerpo aparece, pues, como un espacio donde interseccionan las opresiones y como lugar de resistencia" (Rodó-de-Zárate, 2013, p. 135) y se realiza una apuesta para que sea una escala geográfica, dado que es "el primer espacio en el que construimos nuestras subjetividades", al igual que "los cuerpos no pueden 
ser separados de las experiencias en los espacios y en los lugares" (Jonhston \& Longhurst, 2010, pp. 39-40).

\section{El sesgo androcéntrico y racista en la historiografía sobre esclavitud}

Harding (1987), explicó que definir los hechos sólo desde la perspectiva androcéntrica proporciona una visión muy parcial de la sociedad. En la mayor parte de los escritos sobre esclavitud se ha enmascarado a las esclavas detrás de un relato casi exclusivamente masculino, pues sólo se presenta lo que sucedió con los varones esclavizados, desde una perspectiva androcentrada y se ha demostrado cierta indiferencia respecto al mundo femenino. Vemos cómo para hacer referencia a la población esclava se utilizan los términos "el esclavo", "el negro" "la presencia del negro", (Cortés López, 1986). Lobo Cabrera (2009), en un estudio historiográfico de la esclavitud, presenta un artículo centrado en los hombres esclavos de origen indígena o africano, donde la mención a las esclavas sólo hace referencia a sus nombres. Vicenta Cortés (2011), con un lenguaje que excluye a las mujeres, indica que la esclavitud se ejerce en el hombre. El lenguaje puede ser excluyente si sólo empleamos términos masculinos para designar a toda la población y, no sólo oculta cuáles fueron las realidades de las mujeres en esclavitud, sino que además, ocasiona grandes confusiones. Es difícil dilucidar si la información que se proporciona es aplicable a hombres y a mujeres o si es que éstas últimas no fueron parte de los acontecimientos, o si no figuraban en los documentos históricos que los historiadores han estudiado, o que es cuestión bien de que éstos no las nombran o bien no han sido objeto de investigación.

A modo de ejemplo, aludo a lo visible que es el olvido de las mujeres esclavas en los castigos que recibían, pues encuentro reflexiones como: "la pena de azotes era el castigo más frecuente del esclavo. Había que llevar cuidado de no merecerlos y raro era el varón que se libró de ellos" (Piqueras, 2011, p. 153). Sin embargo, en las cartas de venta analizadas en este artículo figuraba con claridad que las mujeres esclavizadas también podrían ser cuerpo de castigo en el caso de ser reprobada su conducta. Por lo tanto, nos preguntamos ¿cuál ha sido entonces la historia de la esclavitud en la Península Ibérica en los tiempos modernos, teniendo en cuenta también a las mujeres y desde un punto de vista feminista? 
Por otro lado, veo en algunos casos que la metodología empleada en el análisis de los registros históricos hace difícil comprender la implicación de las féminas. Graullera Sanz (1978) presenta tablas de datos que no fueron desagregados por sexos cuando realizó la investigación, por ejemplo, contabiliza el número de esclavos según el color de la piel hallado en los documentos de la Baylía, de forma que quedan expuestos como "negros, blancos, membrillo, mulatos, morenos, claros, llors, oscuros", pero finalmente desconocemos la existencia de las mujeres. La exclusión de las cautivas en el discurso me parece que motiva la pérdida de rigor en la investigación y difunde resultados, en mi opinión, sesgados y androcentristas. Incluso, se ha llegado a considerar que se utilizan "acepciones amplias del término esclavo" porque comprende también "al siervo y al cautivo" pero sin mencionar a las siervas y a las cautivas, deduzco que ninguna de estas designaciones es amplia, pues descarta a las mujeres.

El papel de los hombres esclavizados en la producción agrícola, minera o artesanal pre-industrial ha sido valorado como parte del proceso productivo y creemos que como tal ha de ser analizado también para las mujeres. Cortés López es muy certero explicando la importancia productiva que tuvo la esclavitud, pero excluye a las esclavas en su discurso:

el esclavo no es simplemente objeto de lucro y ostentación, sino que se hace "mano de obra", barata y segura, que permite una producción rentable a quien lo posea y pueda hacerle rendir. En cuanto a mano de obra, entra como objeto en el mercado de trabajo y se vende o compra para producir (Cortés López, 1986, pp. 55$56)$.

Quisiera añadir aquí que las esclavas se compraban y se vendían con los mismos fines. Las esclavizadas trabajaron en una constelación de tareas domésticas, agrícolas, preindustriales y como nodrizas (Martín Casares, 2014b), contribuyendo, por tanto, al desarrollo económico y productivo de las sociedades hispánicas.

Hablamos de un tratamiento o discurso de carácter sexista cuando no se aprecia y sí que se discrimina el trabajo realizado por la población femenina, pues vemos que se desvaloriza la importancia productiva y económica de las tareas domésticas o se atribuye solamente un rol 


\title{
1351 Delicado-Moratalla - Cuerpos racializados
}

reproductivo en la sociedad, una relevancia sólo como madres y cuidadoras, acorde con el estereotipo de género.

Graullera Sanz (1978), realiza un intento de explicar la presencia menos numerosa de esclavas, frente a los esclavos, mediante argumentos que se enmarcarían en una perspectiva sesgada y estereotipada, como es la equiparación de lo femenino con la docilidad:

\begin{abstract}
Si no se traían más mujeres era porque, aunque estas ofrecían ciertas ventajas, como la de ser más dóciles, por otra parte tenían una desventaja: la de su menor utilidad, ya que los esclavos eran destinados, preferentemente, a las labores de peonaje, donde la fuerza y la resistencia, en los trabajos pesados, era fundamental (Graullera Sanz, 1978, p. 129).
\end{abstract}

No existe noticia de que las mujeres en esclavitud no se dedicasen a trabajos que requiriesen una fuerza física considerable, de hecho, fue en la primera convención nacional sobre los derechos de las mujeres en Estados Unidos en 1851, cuando Sojourner Truth rebatió los argumentos que los hombres reunidos allí ofrecían en contra del voto femenino. Ellos exponían que cómo iba a ser posible que las mujeres, las cuales se caracterizaban por una enorme debilidad, pudiesen ejercer el voto. Truth no dudó un instante, en su intervención, se arremangó la camisa para enseñar la musculatura de su brazo: “¡Mírenme, miren mi brazo!” (Davis, 2005, p. 69). A ella nunca nadie le había ayudado a realizar tareas de esfuerzo físico y, sin embargo, ¿acaso no era ella también una mujer?

Para Lobo Cabrera (1993), en el precio de compraventa de una esclava, resulta un factor fundamental su potencial maternidad, pero no hay mención a su capacidad de trabajo y de aporte económico al sistema social y productivo, aspecto que Martín Casares (2014b) identifica como el estereotipo de la improductividad femenina. Al referirse a la esclavitud en las mujeres, Lobo Cabrera (1993) afirma que su labor se centra solamente en las actividades domésticas y reproductivas, dando por sentado que, la compra de una mujer era equivalente y acotada a una vida para el hogar y/o como objeto sexual:

al ser consideradas como vientres para fecundar o productoras de nuevos esclavos, desde el momento en que la mano de obra 
escasea, alcanzan mayor valor, (...) las mujeres son más cotizadas en la Península en casi todos los mercados excepto en el caso valenciano (...) las esclavizadas no solamente cumplen su papel como fieles servidoras, sino como elementos de distinción social y como 'objetos sexuales' (Lobo Cabrera, 1993, p. 302).

En contraste, se ha demostrado que la versatilidad de la fuerza de trabajo de las mujeres en esclavitud era muy apreciada en los mercados esclavistas y que se debe a ello que en la mayor parte de los casos, su precio de compraventa era mayor al de los hombres (Martín Casares, 2000a). Efectivamente, no existen evidencias de que las esclavas tuviesen un gran número de hijos o hijas, sino más bien lo contrario, así se desprende de los registros de bautismos de Extremadura (Periáñez Gómez, 2009a).

En ciudades como Valencia o Sevilla los propietarios no facilitaron los matrimonios ni su procreación, por lo que no se observa ningún deseo explícito de que éstos comprasen a las mujeres con el objetivo de potenciar su fertilidad. Las evidencias demuestran que el valor de compraventa de las cautivas no estuvo vinculado a su capacidad reproductora (Periáñez Gómez, 2009a). Las investigaciones (Martín Casares, 2014a, 2014b) revelan que las actividades productivas de las esclavas en la España moderna fueron muy variadas. Como bien ha comprobado Aurelia Martín Casares (2014a, 2014b), las mujeres esclavizadas solían trabajar en todas las actividades a las que se dedicase la familia que las obtenía, ya fuesen agrícolas, artesanales o comerciales, además de encargarse de todo el trabajo doméstico, especialmente de las tareas más duras, como lavar, planchar y almidonar. No fue extraño que también trabajasen a jornal para otras personas ajenas a la familia, o que fuesen alquiladas como nodrizas para amamantar a las criaturas de otros matrimonios. Espigadoras, hilanderas, coraleras, aguadoras, panaderas, taberneras, hechiceras y prostitutas, Martín Casares (2014b) narra sus hallazgos sobre las labores de las que ha quedado constancia en la documentación histórica.

Considero que si se analiza el precio de compraventa de las cautivas por su valor reproductivo en la mayor parte de los estudios sobre esclavitud, tendría que hacerse referencia también a la capacidad reproductiva de los varones en el mismo análisis, quienes también son seres sexuados y sexuales y poseen, en igual medida que las mujeres, capacidad para ser padres, reproducirse y tener descendencia. 


\section{Delicado-Moratalla - Cuerpos racializados}

He hallado a su vez, que el interés por presentar las profesiones de las personas en esclavitud únicamente se centra en los trabajos que realizaron los hombres en aquellos escritos que no han incluido la perspectiva de género (Cortés Alonso, 2011; Cortés López, 1986; Graullera Sanz, 1978; Lobo Cabrera, 2009), sin prestar atención a las actividades productivas de las mujeres, pues éstas, no son siquiera mencionadas. No hay evocación a la profesión de las esclavas, es más, Cortés López (1999) únicamente señala profesiones derivadas de la esclavitud como labrador, tintorero, arriero y mesonero.

Martín Casares \& García Barranco (2010), sobre las relaciones íntimas entre los compradores de esclavizadas y éstas, explican que la sexualidad de los hombres se ha presentado de una virilidad excesiva, naturalizada como desenfrenada en la historiografía española sobre la esclavitud.

Este supuesto desenfreno sexual que sentían los dueños de las cautivas, al resultarles sus cuerpos muy seductores, coincide con la explicación que presenta Manuel Lobo (1993) sobre las violaciones y abusos cometidos por éstos, es el propio autor quien reproduce, en su argumentación, el estereotipo hipersexualizado de las mujeres negras, describiéndolas como ardientes:

Las esclavas bien por propia voluntad o forzadas cumplían el servicio de satisfacer los apetitos sexuales de sus señores y amigos, algunos de los cuales perdían la cabeza ante las ardientes jóvenes de color repartidas a lo ancho de la geografía hispana (Lobo Cabrera, 1993, p. 308).

En estas palabras, existen matices que inducen a pensar que las jóvenes negras constituían una amenaza contra la tranquilidad sexual de los hombres, que sus cuerpos rompían la armonía e invitaban al desvarío. El autor (Lobo Cabrera, 1993), en su artículo, dice que para las cautivas era normal la explotación sexual a la que eran sometidas. Creemos que lo habitual no lo podemos calificar como normal, pues se transmite con ello una errónea idea de naturalidad, y, por otro lado, queda reflejado una posible asimilación por parte de ellas de permisividad del trato que recibían. Desde su perspectiva, se intuye que considera a las esclavas como sumisas y resignadas, perpetuándolas en un papel poco rebelde y crítico, dentro de 
la idea de feminidad y negritud clásica, asociada a la pasividad y a la bobería.

Sobre el discurso historiográfico desde un análisis que incluya la perspectiva del impacto del racismo en la epistemología occidental, la esclavitud ha llegado a recibir un tratamiento tan desdeñado que incluso ha sido nombrada como "una institución menor", cuando fue, inequívocamente, un hito que marcó a la historia humana. A veces se justifica como una explotación de las personas indiscutiblemente lógica y en otras ocasiones se vierten comentarios estereotipados, como los de Graullera Sanz (1978), que emplea términos no objetivos e inconsistentes, en los que asume el estereotipo de holgazanería o falta de amor al trabajo de negros y moros, y opina que solían exagerar cuando aludían al maltrato recibido.

\section{Conclusiones}

La intersección entre el género y la raza corporalizada en las esclavizadas negro africanas en la villa alicantina ha quedado evidenciada en los documentos históricos conservados, cuyos contenidos han sido presentados con detalle en este artículo. El análisis de los documentos originales de archivo ayuda a fortalecer la comprensión de investigaciones anteriores que han abordado la temática, sumando con ello una contribución al avance de los estudios interseccionales sobre la esclavitud en España. Los estudios de género desde la interseccionalidad se enriquecen cuando indagamos en el pasado, pues con ello, es posible hallar nexos con las situaciones de opresión o marginalidad de las mujeres en la actualidad. La geografía feminista y antirracista encuentra en esta práctica una interesante fuente desde la que es recomendable interrogar las realidades del siglo XXI.

En los documentos de los siglos XVI-XVIII, tanto notariales como inquisitoriales, no se escatimó en apuntar minuciosos detalles sobre los tonos en el color de la piel, lo que fue un modo de distinguir las posiciones sociales, de manera que la diferencia era naturalizada. Sin embargo, al igual que el género, la raza también es una construcción social, sin ninguna validez biológica, pero ha existido una extensa tradición cultural de creer fehacientemente en la división racial de la población, de tal manera que esas explicaciones, participan del proceso de normalización o naturalización de la diferencia, que finalmente alimenta la desigualdad entre 


\section{Delicado-Moratalla - Cuerpos racializados}

personas de diferentes orígenes geográficos. Los tribunales inquisitoriales participaron a su vez de las distinciones raciales, por lo que desprendemos que fue habitual en los documentos administrativos de la era moderna hispánica.

Como hemos probado a lo largo de este texto, la esclavización de mujeres supuso un proceso de normalización de las violencias de género, de la mercantilización de los cuerpos y de la explotación sexual femenina. 


\section{Referencias}

Basset, A. (1677). Venta de una esclava llamada Jusepa $\mathrm{M}^{\mathrm{a}}$. Legajo-19-5510/0. Archivo Municipal de Alicante.

Brahinsky, R., Sasser, J., \& Minkoff-Zern, L.-A. (2014). Race, Space, and Nature: An Introduction and Critique. Antipode, 46(5), 1135-1152. doi: http//doi.org/10.1111/anti.12109

Bru, J. (2006). El cuerpo como mercancía. In Las otras geografías (pp. 465492). Valencia: Tirant Lo Blanch.

Cortés Alonso, V. (1972). Procedencia de los esclavos negros en Valencia (1482-1516). Revista Española de Antropología Americana, 7(1), 123152.

Cortés Alonso, V. (2011). Esclavos y libertos en los mundos ibéricos. Madrid: Mundo Negro.

Cortés López, J. L. (1986). Los orígenes de la esclavitud negra en España. Madrid: Mundo Negro.

Cortés López, J. L. (1999). Los esclavos y la Inquisición (siglo XVI). Studia Historica. Historia Moderna, 20, 217-240.

Crenshaw, K. (1991). Mapping the Margins: Intersectionality, Identity Politics, and Violence Against Women of Color. Stanford Law Review, 43, 1241-1299.

Davis, A. Y. (2005). Mujeres, raza, clase. Madrid: Ediciones Akal.

De Goyeneche, J. (1733). Venta de esclava. Protocolo notarial, signatura 1246/1, escritura 111, pág. 168. Archivo Histórico Provincial de Alicante.

Eurostat. (2015). Trafficking in Human Beings.

Faria, C., \& Mollett, S. (2016). Critical feminist reflexivity and the politics of whiteness in the "field." Gender, Place \& Culture, 23(1), 79-93. doi: http//doi.org/10.1080/0966369X.2014.958065

Federici, S. (2010). Calibán y la bruja. Mujeres, cuerpo y acumulación originaria. Madrid: Traficantes de sueños.

Gillen, J. (2016). Rethinking Whiteness and Masculinity in Geography: Drinking Alcohol in the Field in Vietnam. Antipode, 48(3), 584-602. doi: http//doi.org/10.1111/anti.12202

Gómez de Villanueva, F. (1714). Venta de esclava. Protocolo notarial, signatura 691, escritura 89, págs. 132-133. Archivo Histórico Provincial de Alicante. 
Gómez Grijalba, D. (2012). Mi cuerpo es un territorio político. Brecha lésbica. Retrieved from https://brechalesbica.files.wordpress.com/2010/11/mi-cuerpo-es-unterritorio-polc3adtico77777-dorotea-gc3b3mez-grijalva.pdf

Grassi, J.D. (1723). Venta de esclava. Protocolo notarial, signatura 379-2, escritura 129, págs. 120-121. Archivo Histórico Provincial de Alicante.

Graullera Sanz, V. (1978). La esclavitud en Valencia en los siglos XVI y XVII. Valencia: Instituto Valenciano de Estudios Históricos, Institución Alfonso el Magnánimo, Diputación Provincial, Consejo Superior de Investigaciones Científicas.

Gregory, D., Johnston, R., Pratt, G., Watts, M., \& Whatmore, S. (Eds.). (2009). The Dictionary of Human Geography. West Sussex: WileyBlackwell.

Harding, S. (1987). Is there a feminist method? In Feminism and methodology. Bloomington, Indianapolis: Indiana University Press.

Hill Collins, P., \& Bilge, S. (2016). Intersectionality. Cambridge and Malden: Polity Press.

Inquisición (1625). Proceso de fe de Luisa Núñez. Sección Inquisición, 92/15. Archivo Histórico Nacional.

Inquisición (1624a). Proceso de fe de Valentina Polonia. Sección Inquisición, 93/13. Archivo Histórico Nacional.

Inquisición (1624b). Proceso de fe a Juana de Roda. Sección Inquisición, 2022(2)/37, pp. 25-27.

Jonhston, L., \& Longhurst, R. (2010). Space, Place and Sex. Geographies of sexualities. Plymouth: Rowman \& Littlefield Publishers.

Kobayashi, A. (1995). The Paradox of Difference and Diversity (or, Why the Threshold Keeps Moving). In J. P. Jones III, H. J. Nast, \& S. M. Roberts (Eds.), Thresholds in Feminist Geography (pp. 3-9). Maryland: Rowman \& Littlefield Publishers.

Kobayashi, A. (2006). Why Women of Colour in Geography? Gender, Place \& $\quad$ Culture, 13(1), 33-38. doi: http//doi.org/10.1080/09663690500530941

Kobayashi, A., \& Peake, L. (1994). Unnatural discourse. "Race" and gender in geography. Gender, Place \& Culture, 1(2), 225-243. doi: http:/doi.org/10.1080/09663699408721211

Lerner, G. (1990). La creación del patriarcado. Barcelona: Crítica. 
Lobo Cabrera, M. (1993). La mujer esclava en España en los comienzos de la Edad Moderna. Baetica: Estudios de Arte, Geografía E Historia, 15, 295-316.

Lobo Cabrera, M. (2009). Nombres que se van, nombres que llegan (indígenas canarios, moriscos y negros). El Museo Canario, (64), 183198.

Lugones, M. (2008). Colonialidad y género. Tabula Rasa, 9 julio-di, 73101.

Lugones, M. (2012). Subjetividad esclava, colonialidad de género, marginalidad y opresiones múltiples. In P. MONTES RUIZ (Ed.), Pensando los feminismos en Bolivia (pp. 129-140). La Paz: Conexión Fondo de Emancipación.

Martín Casares, A. (2000a). La esclavitud en la Granada del siglo XVI. Granada: Universidad de Granada. Diputación provincial de Granada.

Martín Casares, A. (2000b). La esclavitud en la Granada del siglo XVI. Género, raza y religión. Granada: Diputación provincial de Granada.

Martín Casares, A. (2014a). Mujeres esclavas y abolicionistas en la España de los siglos XVI al XIX. Madrid: Iberoamericana.

Martín Casares, A. (2014b). Productivas y silenciadas: el mundo laboral de las esclavas en España. In Mujeres esclavas y abolicionistas en la España de los siglos XVI al XIX (pp. 57-94). Madrid: Iberoamericana.

Martín Casares, A., \& García Barranco, M. (2010). La esclavitud negro africana en la historia de España. Siglos XVI y XVII. Granada: Comares. McKittrick, K. (2006). Demonic Grounds. Black Women and the Cartographies of Struggle. University of Minnesota Press.

McKittrick, K., \& Woods, C. (2007). Black Geographies and the Politics of Place. Toronto: Between the Lines.

Méndez Rodríguez, L. (2010). Visiones iconográficas de la esclavitud en España. In A. Martín Casares \& M. García Barranco (Eds.), La esclavitud negroafricana en la historia de España siglos XVI y XVII (pp. 95-126). Granada: Comares.

Mendoza, B. (2014). La epistemología del sur, la colonialidad del género y el feminismo latinoamericano. In Y. Espinosa Miñoso, D. Gómez Correal, \& K. Ochoa Muñoz (Eds.), Tejiendo de otro modo: feminismo, epistemología y apuestas descoloniales en Abya Yala (pp. 135-142). Popayán: Universidad del Cauca. 
Moharam, R. (1999). Black body. Women, colonialism and space. University of Minnesota Press.

Mollett, S. (2016). The Power to Plunder: Rethinking Land Grabbing in Latin America. Antipode, 48(2), 412-432. doi: http//doi.org/10.1111/anti.12190

Mollett, S., \& Faria, C. (2013). Messing with gender in feminist political ecology. Geoforum, 45, 116-125. doi: http//doi.org/10.1016/j.geoforum.2012.10.009

Morgado García, A. (2010). Guerra y esclavitud en el Cádiz de la Modernidad. In La esclavitud negroafricana en la historia de ESpaña. Siglos XVI y XVII (pp. 55-74). Granada: Comares.

Nagel, J. (2003). Race, ethnicity and sexuality. Intimate Intersections, Forbidden Frontiers. New York: Oxford University Press.

Ortiz Guitart, A. (2012). Cuerpo, emociones y lugar: aproximaciones teóricas y metodológicas desde la geografía. Geographicalia, 2012, 115131.

Peake, L., \& Kobayashi, A. (2002). Policies and Practices for an Antiracist Geography at the Millennium. The Professional Geographer, 54(1), 5061. doi: http:/doi.org/10.1111/0033-0124.00314

Peake, L., \& Rieker, M. (2013). Rethinking Feminist Interventions into the Urban. New York: Routledge.

Periáñez Gómez, R. (2009a). Esclavas en extremadura durante la edad moderna. In III Jornadas de Historia de Valencia de las Torres (pp. 4766).

Periáñez Gómez, R. (2009b). Esclavas en Extremadura durante la Edad Moderna. In III Jornadas de Historia en Valencia de las Torres (pp. 4766). Valencia de las Torres.

Piqueras, J. A. (2011). La esclavitud en las españas. Un lazo transatlántico. Madrid: Catarata.

Protocolo notarial (1727). Libertad a esclavo. Carta de libertad, signatura 703, escritura 111, págs. 209-210. Archivo Histórico Provincial de Alicante.

Pulido, L. (2002). Reflections on a White Discipline. The Professional Geographer, 54(1), 42-49. doi: http//doi.org/10.1111/0033-0124.00313

Real Hacienda (1714). Venta de esclavo. Protocolo notarial, signatura 1584, escritura 132, pág. 202. Archivo Histórico Provincial de Alicante. 
GÉNEROS-Multidisciplinary Journal of Gender Studies, 6(2) 1360

Rodó-de-Zárate, M. (2013). Gènere, cos i sexualitat. La joventut, l'experiència i l'ús de l'espai públic urbà. Papers. Revista de Sociologia, 98(1), 127-142.

Staeheli, L. A., Kofman, E., \& Peake, L. (Eds.). (2004). Mapping women, making politics: feminist perspectives on political geography. Routledge. Valentine, G. (2007). Theorizing and Researching Intersectionality: A Challenge for Feminist Geography*. The Professional Geographer, 59(1), 10-21. doi: http//doi.org/10.1111/j.1467-9272.2007.00587.x

Worldwide, W. L. (2014). La trata de mujeres y niñas nigerianas: esclavitud entre fronteras y prejuicios.

\section{Lydia Delicado-Moratalla, profesora de estudios de Género}

\section{Contact address:}

Instituto Universitario de Investigación de Estudios de Género

Universidad de Alicante

Carretera San Vicente s/n

03690 San Vicente del Raspeig

Alicante (Spain)

E-mail address: lydia.delicado@gmail.com 